\title{
Milk fat globule membrane isolated from buttermilk or whey cream and their lipid components inhibit infectivity of rotavirus in vitro
}

\author{
K. L. Fuller, ${ }^{*}$ T. B. Kuhlenschmidt, † M. S. Kuhlenschmidt, ${ }^{\star} †$ R. Jiménez-Flores, $\ddagger$ and S. M. Donovan*1 \\ ${ }^{*}$ Division of Nutritional Sciences, 905 S. Goodwin Avenue, University of Illinois, Urbana 61801 \\ †Department of Pathobiology, 2001 S. Lincoln Avenue, University of Illinois, Urbana 61802 \\ łDairy Science Department and Dairy Products Technology Center, California Polytechnic State University, San Luis Obispo $93407-0257$
}

\section{ABSTRACT}

Milk fat is encapsulated in a milk fat globule membrane (MFGM) that contains bioactive glycoproteins and glycolipids. The MFGM inhibits infectivity of rotavirus (RV), activity that has been attributed to its glycoprotein and carbohydrate components. However, previous studies of proteins and oligosaccharides in the MGFM have not accounted for all the bioactivity associated with the complete MFGM. The lipid fraction of the MFGM accounts for half of its composition by weight, and we postulate that this fraction should be tested by itself to determine if it plays a role in antiviral activity. Herein, the anti-RV activity of an organic extract of MFGM was tested. Natural and whey buttermilk powders containing bovine MFGM enriched in polar lipids were prepared by microfiltration and supercritical fluid extraction treatment to reduce the triglyceride content of the powders. Lipid fractions were then extracted from the MFGM using both single- and dual-phase extraction methods. Whole MFGM and organic extracts were screened in MA-104 cells for anti-infective activity against a neuraminidase-sensitive rotavirus using a focus-forming unit assay. Dose-dependent inhibition was observed for whole buttermilk and cheese whey MFGM against the rotavirus. In general, buttermilk MFGM exhibited greater RV percentage inhibition than cheese whey MFGM. Organic-soluble anti-RV compounds were identified in bovine MFGM. The most active fraction, isolated by dual-phase extraction and iatrobead chromatography, was free of proteins and highly nonpolar. Further separation of this fraction in a less polar solvent (30:1 chloroform:methanol) resolved at least 5 lipid-containing compounds, which likely contribute to the anti-RV activity associated with bovine MFGM. In summary, lipid components associated with MFGM appear to contribute in large part to the anti-RV activity associated with the bovine MFGM.

Received September 4, 2012.

Accepted February 7, 2013.

${ }^{1}$ Corresponding author: sdonovan@illinois.edu
Key words: bovine milk, rotavirus, focus-forming unit assay

\section{INTRODUCTION}

Within milk, high-melting-point triglycerides, phospholipids, and glycosphingolipids are encased in the milk fat globule membrane (MFGM; Keenan and Patton, 1995). The glycosphingolipids and phospholipids account for half of the weight percentage of the membrane and function as intracellular signaling molecules in a variety of biological processes, including regulating cell growth, development, adhesion, and cross membrane trafficking (Astaire et al., 2003). In addition, a variety of bioactive proteins are embedded in the MFGM, including mucin 1 (MUC1), xanthine dehydrogenase/oxidase (XDH/XO), periodic acid Schiff III (PAS III), cluster of differentiation 36 (CD36), butyrophilin (BTN), adipophilin, and periodic acid Schiff 6/7 (Mather, 2000). There is insufficient information on these proteins to characterize their interaction with the lipids that surround them, making it difficult to ascribe specific functions without the potential interference of lipids.

Over the past 2 decades, evidence has accumulated from both in vivo and in vitro studies to suggest numerous potential health benefits associated with MFGM and its associated proteins and fats, including inhibition of gastrointestinal pathogens (Sprong et al., 2002; Spitsberg, 2005), such as Helicobacter pylori (Hirmo et al., 1998; Wang et al., 2001) and rotavirus (RV; Newburg et al., 1998; Kvistgaard et al., 2004).

Worldwide, RV infection is the most common cause of severe dehydrating gastroenteritis (Ramig, 2004; Widdowson et al., 2005). Rotavirus infections are also a concern for agricultural production because of their high incidence in many species of animals, particularly in weanling calves and piglets (Kuhlenschmidt et al., 1999), resulting in an estimated economic loss of $\$ 7$ million each year for producers (House, 1978). Most previous studies have focused on the bioactivities of lactadherin and MUC1, 2 glycoproteins that are associated with the MFGM (Kvistgaard et al., 2004). These 
proteins are thought to bind to pathogens and help remove them from the body via the ciliary action of the gut (Yolken et al., 1992; Kvistgaard et al., 2004). The concentration of lactadherin in human milk varies depending on the stage of lactation; concentrations in colostrum and mature milk average 139 and $66 \mu \mathrm{g} /$ $\mathrm{mL}$, respectively (Peterson et al., 1998). Lactadherin is resistant to digestion in the stomach because of its high degree of glycosylation (Cavaletto et al., 2004). Therefore, it passes into the intestine intact, where it can serve as a binding site for bacterial and viral pathogens (Cavaletto et al., 2004). An epidemiological study of infants infected with human RV showed that infants consuming human milk with a mean lactadherin concentration of $48.4 \mu \mathrm{g} / \mathrm{mL}$ did not exhibit symptoms of RV infection, whereas infants ingesting human milk with a mean concentration of $29 \mu \mathrm{g} / \mathrm{mL}$ were symptomatic for RV infection (Newburg et al., 1998).

Using an in vitro focus-forming unit (FFU) assay, Kvistgaard and colleagues (2004) found that $20 \mu \mathrm{g}$ of human lactadherin/mL inhibited RV infectivity by $50 \%$ in Caco-2 cells infected with the WA strain of human RV. In addition, they quantified and isolated bovine milk lactadherin. Bovine milk lactadherin concentrations were comparable to those in human milk; however, isolated bovine lactadherin did not inhibit infectivity of neuraminidase-sensitive or neuraminidaseinsensitive strains of RV (Kvistgaard et al., 2004). This led the authors to propose that other components of the bovine MFGM could be responsible for its anti-RV activity. Indeed, anti-RV components were identified in whole bovine MFGM and macromolecular whey proteins (MMWP). Bovine mucin, MUC1, is among the major components of MFGM and MMWP. It is a highmolecular-weight, heavily glycosylated protein that exists in a viscous gel in vivo (Mather, 2000). As a result, MUC1 binds to and sequesters pathogenic microorganisms, such as RV and Escherichia coli, thus inhibiting their ability to damage the gut epithelium (Schroten et al., 1992; Yolken et al., 1992). When MUC1 isolated from bovine MFGM was tested for anti-RV activity in an FFU assay, a concentration of $6.3 \mu \mathrm{g}$ of MUC1/ $\mathrm{mL}$ reduced $\mathrm{RV}$ infectivity by $62.5 \%$ (Kvistgaard et al., 2004). In human milk, the oligosaccharides contained on MUC-1 include fucose, $\mathrm{N}$-acetylgalactosamine, $\mathrm{N}$ acetylglucosamine, galactose, and sialic acid. The $N$ linked carbohydrate moieties that contain sialic acid at their nonreducing end appear to be responsible for the virus-inhibitory activity (Yolken et al., 1992; Newburg et al., 1998). A subsequent study identified immunoglobulin as the primary anti-RV factor in the MMWP (Bojsen et al., 2007).

In the current study, the potential for MFGM to inhibit RV infection was investigated, because compo- nents of bovine (Kvistgaard et al., 2004) and human (Newburg et al., 1998) MFGM have been shown to exert anti-RV activity. We compared MFGM isolated from buttermilk or cheese whey buttermilk by microfiltration and supercritical fluid extraction (SFE). This process selectively extracts triglycerides, which leads to enrichment of polar and more complex lipids in the MFGM (Astaire et al., 2003). This extraction method also results in the selective fractionation of various lipids without the use of conventional toxic solvents (Astaire et al., 2003). Using buttermilk as a source for these lipids as viral inhibitors is a sound strategy considering its unique properties as a functional food ingredient and its low cost and availability (Walstra et al., 1999; USDA-NASS, 2001). We hypothesized that MFGM isolated by SFE would inhibit RV infectivity and that this effect would be due, in part, to the enriched lipid components.

\section{MATERIALS AND METHODS}

\section{Concentration of MFGM in Natural and Whey Cream Buttermilks}

Milk (500 L) for each batch of buttermilk was obtained from the Cal Poly Dairy Farm (San Luis Obispo, CA). The skim milk was separated from the cream by a pilot-plant cream separator (DeLaval, Kansas City, $\mathrm{MO})$. Whey cream for this experiment was produced and donated by Hilmar Co. (Hilmar, CA) and 3 batches of cream $(120 \mathrm{~L})$ were used. The cream was treated in the pilot plant at Cal Poly and subjected to regular pasteurization: $77.5^{\circ} \mathrm{C}\left(172^{\circ} \mathrm{F}\right)$ for $15 \mathrm{~s}$. Buttermilk was pasteurized before storage at $75^{\circ} \mathrm{C}\left(169^{\circ} \mathrm{F}\right)$ for 15 $\mathrm{s}$. The cream was processed into butter at $12^{\circ} \mathrm{C}$ using a continuous churn (Egli Co., Gumligen, Switzerland), and buttermilk and whey buttermilk were collected. Buttermilk for each sample was recovered in milk cans, small fat grains or aggregates were removed by filtration through cheese cloth, and the resulting buttermilk was passed through the cream separator again. The buttermilks were stored overnight at $4^{\circ} \mathrm{C}$ until membrane filtration was performed.

A pilot-plant scale system (R-12 model, GEA-Niro Filtration, Hudson, WI) with 2 spiral-wound polymeric membranes fitted in parallel on the module $(10 \mathrm{kDa}$ molecular mass cutoff, $11.33 \mathrm{~m}^{2}$ total surface area) was used to remove most of the mineral salts, lactose, and free oligosaccharides. The process was carried out at $25^{\circ} \mathrm{C}$; the trans-membrane pressure was $600 \mathrm{kPa}$, and the feed pump, attached to a frequency drive, was operated at $35 \mathrm{~Hz}$. Microfiltration was conducted until a 10fold volumetric concentration factor was reached. Diafiltration was done while continuously adding purified 
water at $25^{\circ} \mathrm{C}$ to the feed tank to replace the removed permeate until a 5 -fold diafiltration factor was reached. In each step of the filtration, samples of retentates were collected for composition. The final retained fractions from all experiments were spray-dried (NiroFilterlab Spray-Drier, Hudson, WI) using 3,500 kPa of pressure, and inlet and outlet air temperatures of $175^{\circ} \mathrm{C}$ and $90^{\circ} \mathrm{C}$, respectively, to obtain buttermilk powder $(\mathbf{B M})$ and cheese whey buttermilk powder $(\mathbf{C W})$. All runs were performed in triplicate.

Each buttermilk powder was submitted to SFE to remove residual triglycerides from the samples. The SFE system and components were acquired from Thar Designs Inc. (Pittsburgh, PA), including the 500-mL sample vessel, the model P-50 high-pressure pump, the automated back pressure regulator (model BPR-A200B), and the PolyScience water bath and pump unit (model 9505; PolyScience, Niles, IL). Circulated deionized water at $3^{\circ} \mathrm{C}$ was used to cool different zones in the SFE apparatus. Carbon dioxide tanks were filled and inspected by A\&R Welding Supply (San Luis Obispo, $\mathrm{CA}$ ). The system conditions were controlled manually by Windows 2000-based software (Hewlett-Packard, Palo Alto, CA). Approximately $200 \mathrm{~g}$ of each sample was submitted to 3 extraction cycles using the following conditions: $1,500 \mathrm{~g}$ of $\mathrm{CO}_{2}$ at a flow rate of $20 \mathrm{~g} /$ min, extraction pressure of $35 \mathrm{MPa}$, and extraction and collection temperatures of $50^{\circ} \mathrm{C}$. The SFE trials were done in triplicate. All the powders were stored in a humidity-controlled chamber at $10^{\circ} \mathrm{C}$.

\section{Organic Extraction of Lipids from MFGM}

Single-Phase Lipid Extraction and Thin Layer Chromatography. A lipid extraction was performed on each MFGM-enriched powder using the method of Svennerholm and Fredman (1980). Briefly, each powder $(75 \mathrm{mg})$ was suspended in water $(0.75 \mathrm{~mL})$ and vigorously mixed. While mixing, methanol $(2 \mathrm{~mL})$ was slowly added followed by chloroform $(1 \mathrm{~mL})$ to make a chloroform:methanol:water mixture of 1:2:0.75. This mixture was centrifuged $\left(1,000 \times g, 5 \mathrm{~min}, 4^{\circ} \mathrm{C}\right)$, the pellet discarded, and the supernatant collected. Portions of the supernatant were evaporated and suspended in either solvent (thin layer chromatography, TLC) or minimal essential medium (MEM; focus-forming unit) assays. Lipids were separated by silica gel TLC using a 55:45:10 ratio of chloroform to methanol to water. Lipids were fluorescently detected with primulin (White et al. 1998) and carbohydrates were detected with orcinol in sulfuric acid. Lactose, cholesterol, and the ganglioside GM3 were run as standards.

Dual-Phase Lipid Extraction and Iatrobead Chromatography. To better separate the lipid com- ponents of the MFGM, a dual-phase lipid extraction was performed on each powder (Folch et al., 1957) followed by chromatography. Milk fat globule membrane $(1 \mathrm{~g})$ was suspended in $10 \mathrm{~mL}$ of water and mixed. While mixing, methanol $(16.65 \mathrm{~mL})$ was slowly added followed by chloroform $(33.33 \mathrm{~mL})$. The mixture was centrifuged $\left(1,000 \times g, 10 \mathrm{~min}, 4^{\circ} \mathrm{C}\right)$, producing an aqueous upper layer, a white interface, and a lower chloroform layer. The upper aqueous layer was removed and the lower chloroform layer was collected by carefully inserting a Pasteur pipette through the interface layer. The remaining interface layer was extracted 2 times by adding water $(4.5 \mathrm{~mL})$ followed by $22.5 \mathrm{~mL}$ of a chloroform:methanol $(2: 1)$ solution. After centrifugation, the upper layer was combined with the first aqueous layer and the lower layer was combined with the first chloroform layer. The combined upper layer was concentrated by rotary evaporation to $16 \mathrm{~mL}$, and $80 \mathrm{~mL}$ of a chloroform:methanol (2:1) solution was added, the mixture centrifuged as above, and the upper and lower layers collected. Likewise, the combined lower layers from the first extraction were evaporated to dryness, suspended in $6 \mathrm{~mL}$ of water, and then 30 $\mathrm{mL}$ of a chloroform:methanol (2:1) solution was added. After centrifugation, all of the upper and lower layers were separately combined. Then, the combined aqueous layer was concentrated by rotary evaporation to $10 \mathrm{~mL}$ and the lower organic layer was evaporated to dryness.

For initial separation of lipids, the organic phase was applied to an iatrobead column equilibrated in a chloroform:methanol (95:5) solution and eluted using modifications of a previously described procedure (Rolsma et al., 1998). Briefly, the dried organic layer (1 $\mathrm{g}$ of MFGM equivalent) was dissolved in $5 \mathrm{~mL}$ of a chloroform:methanol (4.5:1) solution and centrifuged to remove any precipitate. The supernatant was applied to the iatrobead column and eluted with a 4.5:1 chloroform:methanol solution; nine 100-mL fractions were collected. The eluant was then changed to a 1:1 chloroform:methanol solution and seven $100-\mathrm{mL}$ fractions were collected. All fractions were dried by rotary evaporation, the 9 samples eluted with chloroform methanol 4.5:1 were suspended with $1 \mathrm{~mL}$ of chloroform:methanol 4.5:1, and the 7 fractions eluted with chloroform:methanol 1:1 were suspended with 1 $\mathrm{mL}$ of chloroform:methanol 1:1. Portions were analyzed by TLC, SDS-PAGE, and FFU assays.

SDS-PAGE Separation of MFGM. Samples from both single- and dual-phase extractions were dried under nitrogen in microfuge tubes followed by addition of $2.5 \mu \mathrm{L}$ of $4 \times$ NuPage sample buffer (Invitrogen Inc., Carlsbad, CA), $6.5 \mu \mathrm{L}$ of water, and $1 \mu \mathrm{L}$ of $\beta$-mercaptoethanol. The tubes were heated at $70^{\circ} \mathrm{C}$ for $10 \mathrm{~min}$ and, after cooling, $10 \mu \mathrm{L}$ of the sample was ap- 
plied to a NuPage 10\% BisTrispolyacrylamide gel (Invitrogen Inc.) and separated by electrophoresis at 200 $\mathrm{V}$ for $50 \mathrm{~min}$. SeeBlue molecular weight standards were obtained from Invitrogen Inc., and gels were stained with Coomassie Blue to visualize proteins.

\section{Rotavirus Preparation and FFU Assay}

To assess the anti-RV potential of MFGM, in vitro studies were performed using MA-104 cells derived from embryonic African green monkey kidney cells (BioWhittaker, Walkersville, MD), as previously described (Rolsma et al., 1994; Andres et al., 2007). A neuraminidase-sensitive, Group A porcine RV strain (OSU-RV) serotype P9[7]G5 was propagated in MA104 cells, purified as described Rolsma et al. (1994), and used for the in vitro experiments.

An FFU assay to measure RV infectivity in the presence or absence of MFGM fractions was performed as described previously (Rolsma et al., 1998). Briefly, $125 \mu \mathrm{L}$ containing the desired amount of MFGM fraction in MEM or MEM alone was mixed with an equal volume of RV containing approximately 1,000 FFU of infectious activity. This inhibitor-RV mixture was incubated for $30 \mathrm{~min}$ at $23^{\circ} \mathrm{C}$, before applying $100 \mu \mathrm{L}$ to duplicate wells in 24-well plates containing confluent MA-104 cell monolayers that had been rinsed free of serum with PBS. After adsorption to the MA-104 cell layer for $30 \mathrm{~min}$ at $37^{\circ} \mathrm{C}$, the RV-MFGM inoculum was removed. After rinsing the cell layer with PBS, MEM without serum was added to each well and the plate was incubated at $37^{\circ} \mathrm{C}$ for 16 to $18 \mathrm{~h}$. Immunochemical detection of rotavirus infectivity was performed as described (Rolsma et al., 1998). Results for inhibition by single- or dual-phase extracts are expressed as relative to the total weight of lipids isolated from the MFGM powders.

\section{Statistical Analysis}

Statistical analyses were performed using the PROC GLM (generalized linear model) procedure within SAS (version 9.2, SAS Institute Inc., Cary, NC) with a post hoc LSD test using Fisher's least significant difference test to evaluate the effect of treatment. Statistical significance was defined as $P<0.05$. All data are expressed as means \pm SEM.

\section{RESULTS}

\section{Composition of the BM and CW Powders Used to Isolate MFGM}

The major components of the buttermilk powders after SFE are shown in Table 1. Total solids, protein, fat, and ash contents were measured. The phospholipids are listed separately, but were part of the total fat in the sample. The observed difference in protein:fat ratio of $\mathrm{BM}$ compared with $\mathrm{CW}$ has been discussed elsewhere (Astaire et al., 2003; Gallier et al., 2010) and seems to be a result of how the combination of processes act upon the different substrates. For example, casein-containing BM appeared to retain more total lipids (including triglycerides), whereas the whey-cream buttermilk seemed to preferentially attach to phospholipids and whey protein aggregates. The source of the whey protein aggregates is currently not known, but they may be produced during processing.

\section{Comparison of BM and CW Powders on Anti-RV Infectivity}

Both whole BM and CW powders containing MFGM inhibited the infectivity of the neuraminidase-sensitive OSU-RV strain in a dose-dependent manner, at doses as low as $0.1 \mathrm{mg} / \mathrm{mL}$ (Table 2). Furthermore, $94 \%$ inhibition of RV infectivity was observed with $10 \mathrm{mg} / \mathrm{mL}$ BM MFGM and 81\% inhibition was found with $13 \mathrm{mg} /$ mL CW MFGM.

\section{Isolation of MFGM Lipids by Single-Phase Extraction and Screening for Anti-RV Activity}

Organic solvent extraction of MFGM using a singlephase extraction procedure (Svennerholm and Fredman, 1980) was performed to isolate lipid components of the MFGM and to evaluate their anti-RV activity.

Table 1. Composition of buttermilk and whey buttermilk powders used for isolation of milk fat globule membrane

\begin{tabular}{lcccc}
\hline Powder $^{1}$ & $\begin{array}{c}\mathrm{TS}^{2} \\
(\% \mathrm{DM})\end{array}$ & $\begin{array}{c}\text { Protein } \\
(\% \text { of TS })\end{array}$ & $\begin{array}{c}\text { Ash } \\
(\% \text { of TS })\end{array}$ & $\begin{array}{c}\text { Fat } \\
(\% \text { of TS })\end{array}$ \\
\hline SFE-BM & 94.5 & 61.5 & 4.5 & $26.5(12 \% \text { PL })^{3}$ \\
SFE-CW & 95.0 & 72.7 & 3.3 & $20.5(12.1 \%$ PL $)$ \\
\hline
\end{tabular}

${ }^{1} \mathrm{SFE}-\mathrm{BM}=$ supercritical fluid extracted $\left(\mathrm{CO}_{2}\right)$-buttermilk powder; SFE-CW = supercritical fluid extracted $\left(\mathrm{CO}_{2}\right)$-cheese whey cream buttermilk powder.

${ }^{2}$ Lactose makes up difference in weight to equate to total solids.

${ }^{3}$ Phospholipids (PL) are part of the total lipids. 
Table 2. Effect of exposure to whole milk fat globule membrane (MFGM) isolated from either buttermilk (BM) or cheese whey (CW) on the infectivity of the neuraminidase-sensitive rotavirus strain $(\mathrm{OSU}-\mathrm{RV})^{1}$

\begin{tabular}{lc}
\hline Item & $\begin{array}{c}\text { \% of MEM } \\
\text { control }\end{array}$ \\
\hline MEM control & $100 \pm 2.3^{\mathrm{a}}$ \\
BM MFGM dose & $69 \pm 3.0^{\mathrm{b}}$ \\
$0.1 \mathrm{mg} / \mathrm{mL}$ & $38 \pm 4.0^{\mathrm{c}}$ \\
$0.7 \mathrm{mg} / \mathrm{mL}$ & $30 \pm 7.8^{\mathrm{c}}$ \\
$1.4 \mathrm{mg} / \mathrm{mL}$ & $11 \pm 4.8^{\mathrm{d}}$ \\
$3.4 \mathrm{mg} / \mathrm{mL}$ & $6 \pm 2.1^{\mathrm{d}}$ \\
$10.0 \mathrm{mg} / \mathrm{mL}$ & $5 \pm 0.5^{\mathrm{d}}$ \\
$17.0 \mathrm{mg} / \mathrm{mL}$ & \\
CW MFGM dose & $63 \pm 5.0^{\mathrm{b}}$ \\
$0.1 \mathrm{mg} / \mathrm{mL}$ & $42 \pm 4.0^{\mathrm{c}}$ \\
$0.5 \mathrm{mg} / \mathrm{mL}$ & $38 \pm 3.5^{\mathrm{cd}}$ \\
$1.2 \mathrm{mg} / \mathrm{mL}$ & $30 \pm 5.9^{\mathrm{cde}}$ \\
$2.6 \mathrm{mg} / \mathrm{mL}$ & $25 \pm 3.2^{\mathrm{de}}$ \\
$7.8 \mathrm{mg} / \mathrm{mL}$ & $19 \pm 0.5^{\mathrm{e}}$ \\
$13.0 \mathrm{mg} / \mathrm{mL}$ & \\
\hline
\end{tabular}

${ }^{\mathrm{a}-\mathrm{e}}$ Means with different superscripts differ at $P<0.05$.

${ }^{1}$ Percentage infectivity relative to that of minimal essential medium (MEM) control measured using focus-forming unit assay; means \pm $\mathrm{SEM} ; \mathrm{n}=4$ wells per dose.

Separation by TLC of single-phase extracts of BM and CW MFGM lipids is shown in Figure 1. Both MFGM sources contained some residual lactose and, although the lipid separation profiles were similar, BM MFGM contained several glycolipids in higher amounts than did CW MFGM (arrows).

The single-phase organic extract was screened for anti-RV activity in the FFU assay (Table 3), and the data indicate that the organic solvent extract retained the inhibitory activity. Compared with whole MFGM, the BM MFGM organic extract dose-dependently reduced OSU-RV infectivity over a range of 0.2 to 3.0 $\mathrm{mg} / \mathrm{mL}$ of the total weight of lipids isolated from the BM MFGM powder equivalents, although no further reduction was observed between 3 and $10 \mathrm{mg} / \mathrm{mL}$ (Table 3). The organic extract of CW MFGM displayed a similar trend. The results of initial fractionation experiments demonstrated that virus inhibitory activity was recovered in the organic solvent extract (Table 3), suggesting that MFGM lipids may be responsible for the inhibitory activity.

\section{Further Purification of Lipids by Dual-Phase Extraction and Screening for Anti-RV Activity}

Although the single-phase organic extract of the MFGM showed anti-RV activity, the single-phase procedure was insufficient to remove proteins that could contribute to antiviral activity, as shown in Figure 2. Both $\mathrm{BM}$ and CW MFGM were subjected to a dual-phase organic (Folch) extraction (Folch et al., 1957). The SDSPAGE separation of the 2 lipid extraction methods of

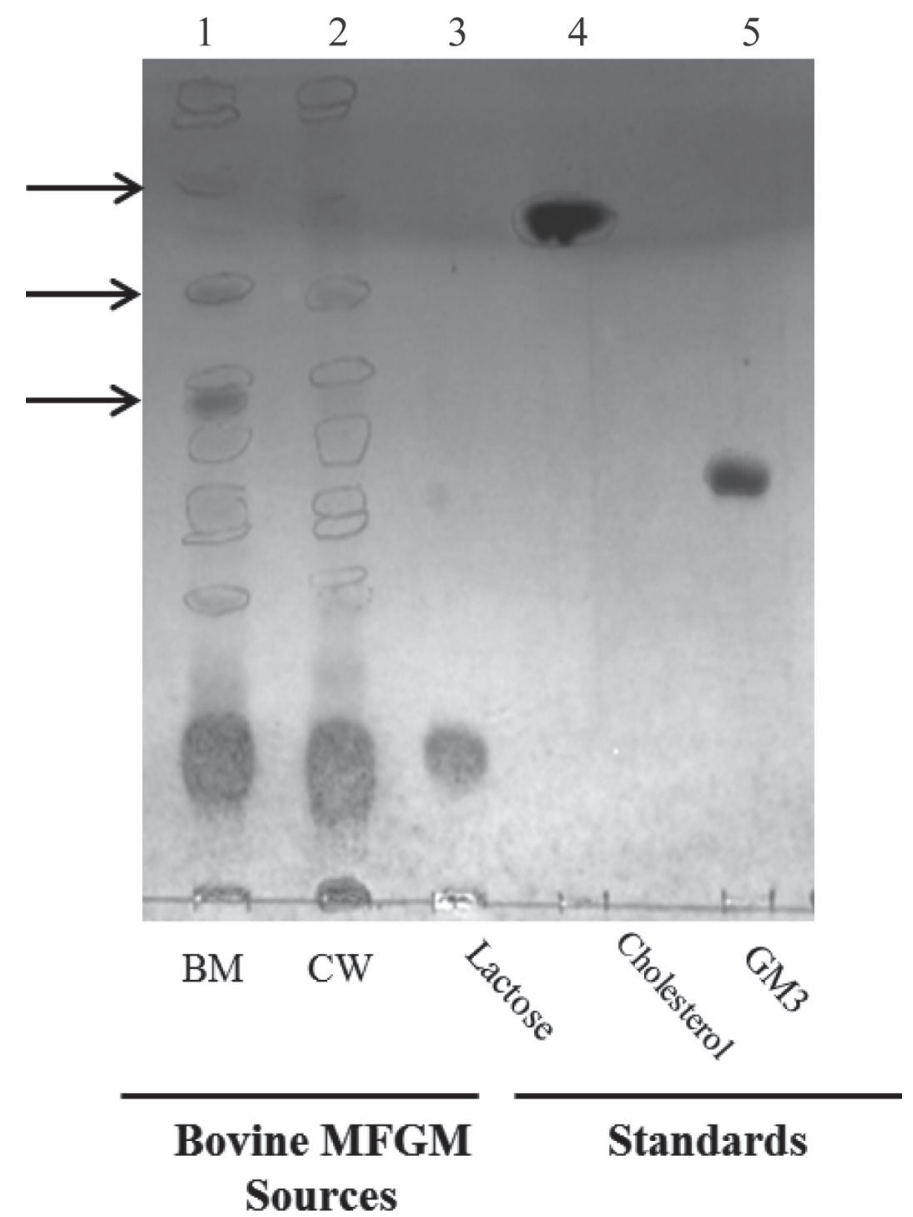

Figure 1. Thin layer chromatographic (TLC) separation of buttermilk (BM) and cheese whey (CW) milk fat globule membrane (MFGM). Single-phase organic extracts of BM MFGM (lane 1) and CW (lane 2), $0.3 \mathrm{mg}$ of dry weight equivalent of each, were separated by silica gel TLC using chloroform:methanol:water (55:45:10). Lipids were fluorescently detected with primulin (circled bands) and carbohydrates were detected with orcinol in sulfuric acid. Lactose $(22 \mathrm{nmol}$, lane 3), cholesterol (13 nmol, lane 4), and ganglioside GM3 (10 nmol, lane 5) were run as standards. Arrows indicate orcinol-staining bands that were enriched in BM MFGM compared with CW MFGM. This image is representative of several experiments.

BM MFGM (left panel) and CW MFGM (right panel) are compared in Figure 2. Whole MFGM (lane 2) was compared with dual-phase (lanes 3-6) and single-phase (lane 7) extractions for each. Protein was detected in the organic extract of the single-phase extraction (lane 7) and in the aqueous phase of the dual-phase extraction (lane 3). Several proteins were seen in the aqueous phase or interface of the BM MFGM. These proteins included those with molecular weights $>198 \mathrm{kDa}$ and approximately 120, 95, 70, 20, and $14 \mathrm{kDa}$. Based on reported molecular weights of MFGM proteins (Mather, 2000), the top 4 bands likely correspond to MUC1 (170-220 kDa, depending on glycosylation), $\mathrm{XDH} / \mathrm{XO}$ (146 kDa), PAS III (95-100 kDa), and CD36 (76 kDa) 
Table 3. Effect of a single-phase organic extraction on the antiinfective activity of milk fat globule membrane (MFGM) isolated from buttermilk $(\mathrm{BM})$ or cheese whey $(\mathrm{CW})$ against a neuraminidasesensitive rotavirus strain $(\mathrm{OSU}-\mathrm{RV})^{1}$

\begin{tabular}{lc}
\hline Item & $\begin{array}{c}\text { \% of MEM } \\
\text { control }\end{array}$ \\
\hline MEM control & $100 \pm 2.4^{\mathrm{a}}$ \\
BM MFGM dose & \\
$0.2 \mathrm{mg} / \mathrm{mL}$ & $70 \pm 14.2^{\mathrm{b}}$ \\
$0.8 \mathrm{mg} / \mathrm{mL}$ & $42 \pm 7.7^{\mathrm{c}}$ \\
$1.6 \mathrm{mg} / \mathrm{mL}$ & $30 \pm 1.5^{\mathrm{cd}}$ \\
$3.0 \mathrm{mg} / \mathrm{mL}$ & $15 \pm 1.2^{\mathrm{d}}$ \\
$10 \mathrm{mg} / \mathrm{mL}$ & $12 \pm 3.0^{\mathrm{d}}$ \\
$\mathrm{CW} \mathrm{MFGM} \mathrm{dose}{ }^{2}$ & $68 \pm 20^{\mathrm{b}}$ \\
$0.2 \mathrm{mg} / \mathrm{mL}$ & $49 \pm 10.1^{\mathrm{bc}}$ \\
$0.8 \mathrm{mg} / \mathrm{mL}$ & $20 \pm 0^{\mathrm{cd}}$ \\
$1.6 \mathrm{mg} / \mathrm{mL}$ & $22 \pm 3.8^{\mathrm{d}}$ \\
$3.0 \mathrm{mg} / \mathrm{mL}$ & $29 \pm 1.5^{\mathrm{cd}}$ \\
$10.0 \mathrm{mg} / \mathrm{mL}$ &
\end{tabular}

${ }^{\mathrm{a}-\mathrm{d}}$ Means with different superscripts differ at $P<0.05$.

${ }^{1}$ Percentage infectivity relative to that of minimal essential medium (MEM) control measured using focus-forming unit assay; mean \pm SEM; $\mathrm{n}=4$ to 6 wells per dose.

${ }^{2}$ Relative to the total weight of lipids isolated from the MFGM powders.

or BTN (66-67 kDa), although this was not verified by sequencing. The 2 lower molecular weight bands are unknown, but could correspond to whey proteins such as $\beta$-LG (18.4 kDa) and $\alpha$-LA (14 kDa). However, protein was absent from the organic layer of the dual-phase extraction for both BM and CW MFGM (lane 4).

The aqueous and organic phase extracts of the MFGM were screened in the FFU assay to differentiate the anti-RV activity of the protein and lipid components, respectively (Table 4). The organic phase retained the anti-RV activity, whereas the aqueous phase did not significantly inhibit RV at any concentration tested. These results agreed with the initial hypothesis that lipids are the major component responsible for the antiviral activity of MFGM.

\section{Separation of Polar and Nonpolar Lipids of the Dual-Phase Organic Extract and Screening for Anti-RV Activity}

The organic extract obtained from the dual-phase extraction method was separated into relatively nonpolar (4.5:1) to polar (1:1) chloroform:methanol fractions by iatrobead chromatography. The resulting fractions were analyzed by TLC (Figure 3) and then screened in the FFU assay (Table 5). The top 3 glycolipid bands (numbered top to bottom as seen in the starting material, Figure 3, lane 1) contained in the BM MFGM were highly nonpolar and eluted from the iatrobead column in fraction 1 . Fractions 2 through 5 contained varying proportions of bands 3 through 6 ; very little of the MFGM glycolipids eluted after frac- tion 5. When the iatrobead elution solvent was changed to 1:1 (chloroform:methanol), an additional 5 bands were eluted, several of which were highly glycosylated (orcinol staining).

As shown in Table 5, most of the anti-RV activity of the lipids isolated from the BM MFGM powder eluted in nonpolar fraction 1 , although the other fractions inhibited, on average, $50 \%$ of the RV infectivity compared with the MEM control. To further separate the lipid components in this fraction containing the highest level of anti-RV activity, fraction 1 from the iatrobead column was separated by silica gel high-performance TLC using a 30:1 (chloroform:methanol) solvent (Figure 4). In this solvent system, the active fraction separated into at least 5 primulin-staining (lipid-containing) bands.

\section{DISCUSSION}

Previous studies have identified glycoprotein components of bovine (Kvistgaard et al., 2004; Kuchta et al., 2012; Le et al., 2012) and human (Newburg et al., 1998) MFGM with anti-RV activity; however, little attention has been focused on the lipid components of the MFGM. The lipids that make up the MFGM include phosphatidylcholine, phosphatidyl-ethanolamine, sphingomyelin, phosphatidylinositol, phosphatidylserine, and other glycosphingolipid or phospholipid components in trace amounts, such as gangliosides, sphingosine, and ceramides (Hamosh et al., 1999; Parodi, 1999). We undertook this study of the lipid component of the MFGM based on the results of several clinical and laboratory investigations supporting antiviral and antimicrobial actions of milk fats (Koopman et al., 1984; Hamosh, 1991; Isaacs and Thormar, 1991; Hamosh et al., 1999; Sprong et al., 2001). First, a prospective study of children over the age of $1 \mathrm{yr}$ found that those consuming low fat milk as their only milk source in the $3 \mathrm{wk}$ before illness were at 5 times the risk of requiring a doctor's visit for acute gastrointestinal illness compared with children drinking only whole milk during the same period (Koopman et al., 1984). This increased risk could not be explained by numerous potentially confounding variables or potential biases, nor did it vary by the children's age (Koopman et al., 1984). Second, milk fat glycosphingolipids and triglycerides, particularly those containing C10:0 and C12:0 fatty acids, have been shown to protect against foodborne gastroenteritis (Sprong et al., 2001). These fatty acids, which appear to have both antimicrobial and antiviral activities, may be native in milk or may be produced within the gastrointestinal tract as products of digestion (Hamosh, 1991; Isaacs and Thormar, 1991; Le et al., 2012). Finally, we have shown that gangliosides, which are a minor component of the MFGM, are present in neonatal piglet intestine and serve as 


\section{Buttermilk MFGM}

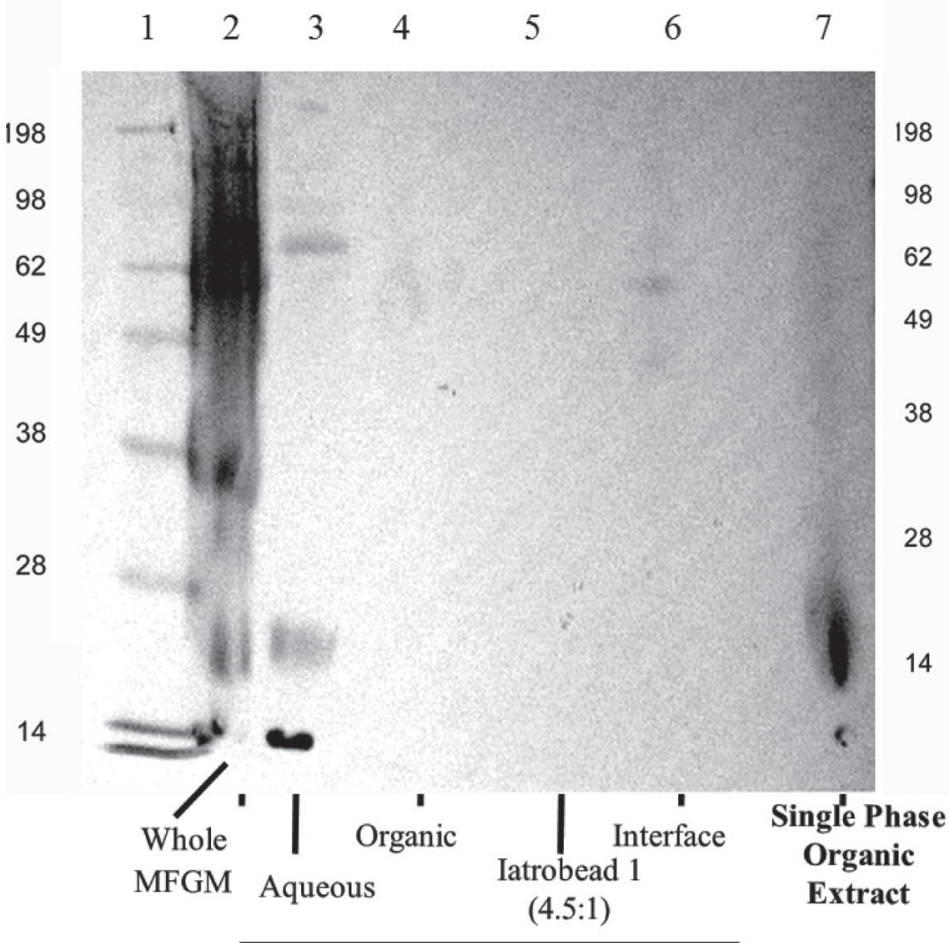

Dual Phase Extraction
Cheese Whey MFGM

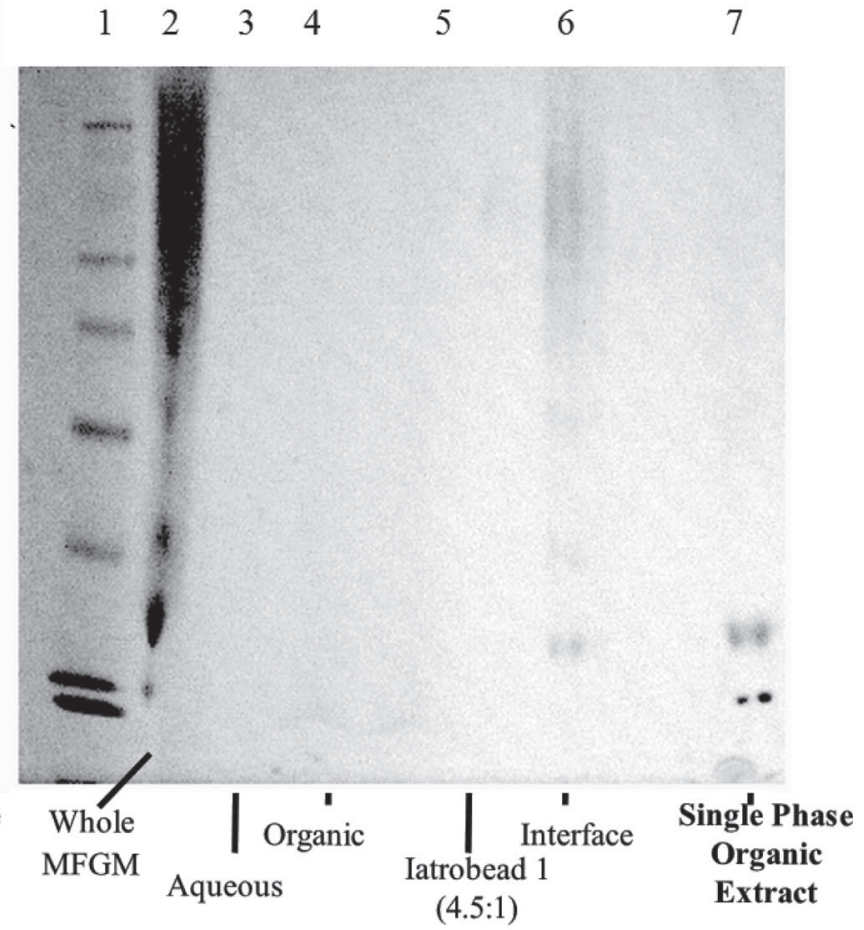

Dual Phase Extraction

Figure 2. Sodium dodecyl sulfate-PAGE of milk fat globule membrane (MFGM) extracts. The MFGM isolated from buttermilk (BM, left panel) and cheese whey (CW, right panel) were separated on a $10 \%$ SDS-PAGE gel and stained with Coomassie blue to visualize proteins. In each panel, lane 1 = molecular weight standard, $10 \mu \mathrm{L}$; lane $2=$ whole MFGM, $0.5 \mathrm{mg}$ of original dry weight equivalent; lane $3=$ dual-phase aqueous extract, $5 \mathrm{mg}$ of original dry weight equivalent; lane $4=$ dual-phase organic extract, $2 \mathrm{mg}$ of original dry weight equivalent; lane $5=$ iatrobead fraction 4.5:1 (1), $25 \mathrm{mg}$ of dry weight equivalent; lane $6=$ dual-phase extraction interface, $0.057 \mathrm{mg}$ equivalent; lane $7=$ single-phase organic extract, $0.5 \mathrm{mg}$ equivalent. Dual phase (lanes 3-6) was compared with single-phase (lane 7) extraction. This is image is representative of several experiments.

specific receptors for sialic acid-dependent group A porcine RV attachment to intestinal epithelial cells (Rolsma et al., 1994, 1998). The 2 major monosialogangliosides both possessed a sialyllactose oligosaccharide moiety characteristic of GM3 gangliosides; however, each ganglioside differed in the type of sialic acid residue it contained (Rolsma et al., 1998). For example, an $\mathrm{N}$-glycolylneuraminic acid moiety was found in the more polar porcine GM3, whereas the less polar GM3 species contained $\mathrm{N}$-acetylneuraminic acid. Both the $\mathrm{N}$ glycolylneuraminic acid GM3 and $N$-acetylneuraminic acid GM3 displayed dose-dependent inhibition of virus binding to cells (Rolsma et al., 1998).

The results herein demonstrated that whole bovine MFGM effectively inhibited a neuraminidase-sensitive strain OSU-RV in vitro. The MFGM isolated from either buttermilk or cheese whey was effective at inhibiting RV infectivity. However, when BM and CW MFGM were tested at similar concentrations, the BM was more effective than CW MFGM at inhibiting RV infectivity, which may reflect the greater complexity of the fatty acid composition of BM MFGM. In particular, glycolipids are more abundant and diverse in BM than in CW MFGM (Gallier et al., 2010).

To determine the potential for lipids associated with the MFGM to inhibit RV infectivity, the MFGM preparations were subjected to single and double organic phase extractions. The extract resulting from a singlephase extraction was enriched in polar lipids, but also contained some proteins. Although the extract retained the ability to inhibit RV in the FFU assay, this activity could not be solely attributed to the lipid components. Thus, a dual-phase extraction procedure was applied that separated the lipid components from the proteins, which were recovered in the aqueous phase and at the interface between the phases. When the lipid and aqueous phases were compared, all anti-RV activity was recovered in the lipid phase, whereas the aqueous phase did not exert any anti-RV activity. This observation was consistent with that of Kvistgaard and colleagues (2004), who found that bovine lactadherin did not inhibit RV after it was purified from the MFGM. The 
ability of bovine lactadherin to exert its action might be dependent upon its structural conformation when it is present within the MFGM and that conformation is lost upon its isolation. One such example may be the activity of $\alpha$-lactalbumin in the presence of oleic acid to form HAMLET or BAMLET ( human, or bovine, alphalactalbumin made lethal to tumor cells), and a further formation of annular oligomers with phospholipids that may explain its function (Baumann et al., 2012).

To further separate the lipids present in the dual-phase extraction, the protein-free lipid extract with anti-RV activity was applied to an iatrobead column, and lipids were eluted in a stepwise fashion moving from relatively nonpolar to more polar solvents. The fraction with the greatest anti-RV activity eluted from the column in the first fraction in a 4.5:1 chloroform:methanol solvent, suggesting that it was relatively nonpolar. The lipids in this fraction inhibited $95 \%$ of the RV infectivity in the FFU assay. Further TLC separation of this fraction using a nonpolar solvent, 30:1 chloroform:methanol, resolved at least 5 lipid-containing compounds less polar than simple gangliosides and phospholipids. It is unclear if the SFE treatment would have made a difference because it removed a large part of nonpolar lipids.

The current study demonstrates that it is the lipid component of the MFGM that has anti-RV activity. This is consistent with some reports in the literature that suggest that milk fat sphingolipids and triglycer-
Table 4. Effect of dual-phase organic extraction on the anti-infective activity of milk fat globule membrane (MFGM), isolated from cheese whey $(\mathrm{CW})$ or buttermilk $(\mathrm{BM})$ against a neuraminidase-sensitive rotavirus strain $(\mathrm{OSU}-\mathrm{RV})^{1}$

\begin{tabular}{lc}
\hline Item & $\begin{array}{c}\text { \% of MEM } \\
\text { control }\end{array}$ \\
\hline MEM control & $100 \pm 2.0^{\mathrm{a}}$ \\
CW organic extract dose & \\
$0.8 \mathrm{mg} / \mathrm{mL}$ & $99 \pm 35.5^{\mathrm{a}}$ \\
$2.0 \mathrm{mg} / \mathrm{mL}$ & $34 \pm 16.5^{\mathrm{b}}$ \\
$6.0 \mathrm{mg} / \mathrm{mL}$ & $13 \pm 4.5^{\mathrm{b}}$ \\
$10.0 \mathrm{mg} / \mathrm{mL}$ & $13 \pm 2.0^{\mathrm{b}}$ \\
$\mathrm{CW} \mathrm{aqueous}$ extract dose & \\
$0.8 \mathrm{mg} / \mathrm{mL}$ & $113 \pm 12.0^{\mathrm{a}}$ \\
$2.0 \mathrm{mg} / \mathrm{mL}$ & $81 \pm 30^{\mathrm{a}}$ \\
$6.0 \mathrm{mg} / \mathrm{mL}$ & $109 \pm 15.0^{\mathrm{a}}$ \\
$10.0 \mathrm{mg} / \mathrm{mL}$ & $86 \pm 15.0^{\mathrm{a}}$ \\
& \\
$\mathrm{MEM} \mathrm{control}$ & $100 \pm 13.0^{\mathrm{a}}$ \\
$\mathrm{BM} \mathrm{organic} \mathrm{extract} \mathrm{dose}$ & \\
$0.2 \mathrm{mg} / \mathrm{mL}$ & $82 \pm 7^{\mathrm{a}}$ \\
$5.0 \mathrm{mg} / \mathrm{mL}$ & $26 \pm 7^{\mathrm{b}}$ \\
BM aqueous extract dose & \\
$20 \mathrm{mg} / \mathrm{mL}$ & $63 \pm 1^{\mathrm{a}}$ \\
\hline
\end{tabular}

${ }^{\mathrm{a}, \mathrm{b}}$ Means within MFGM source $(\mathrm{CW}$ or $\mathrm{BM})$ with different superscripts differ at $P<0.05$.

${ }^{1}$ Percentage infectivity relative to that of minimal essential medium (MEM) control measured using focus-forming unit assay; means \pm SEM of duplicate wells per dose.

${ }^{2}$ Relative to the total weight lipids isolated from the MFGM powders.

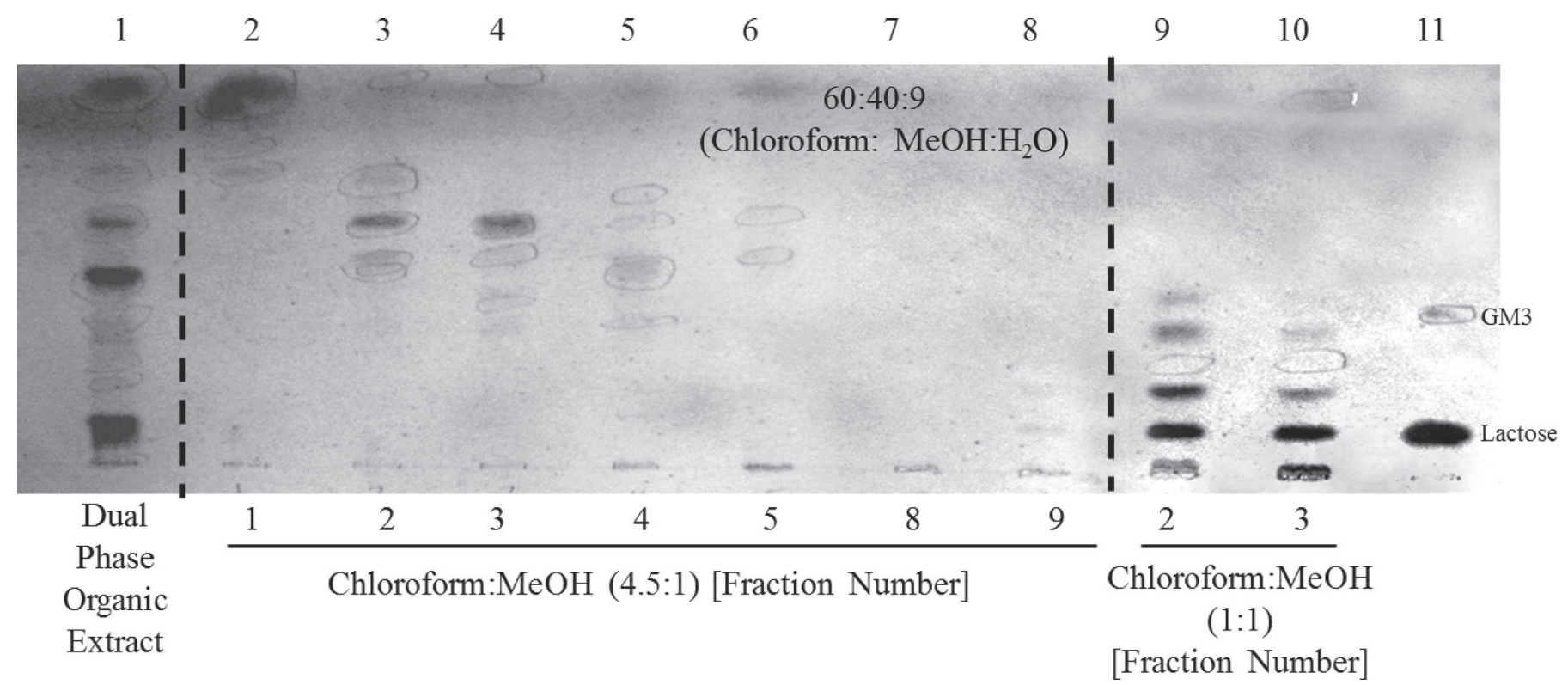

Figure 3. Thin layer chromatographic (TLC) separation of dual-phase extraction of both powders enriched in milk fat globule membrane, natural buttermilk (BM MFGM) and cheese whey-cream buttermilk (CW MFGM), and fractions eluted from the iatrobead column. Whole BM MFGM (lane 1) and iatrobead fractions (1\% of each fraction volume) were applied and separated by silica gel high-performance TLC using chloroform:methanol:water (60:40:9) as the solvent. Lipids were fluorescently detected with primulin (circled bands) and carbohydrates were detected with orcinol in sulfuric acid. Lactose and ganglioside GM3 (lane 11) were run as standards. This image is representative of several experiments. 


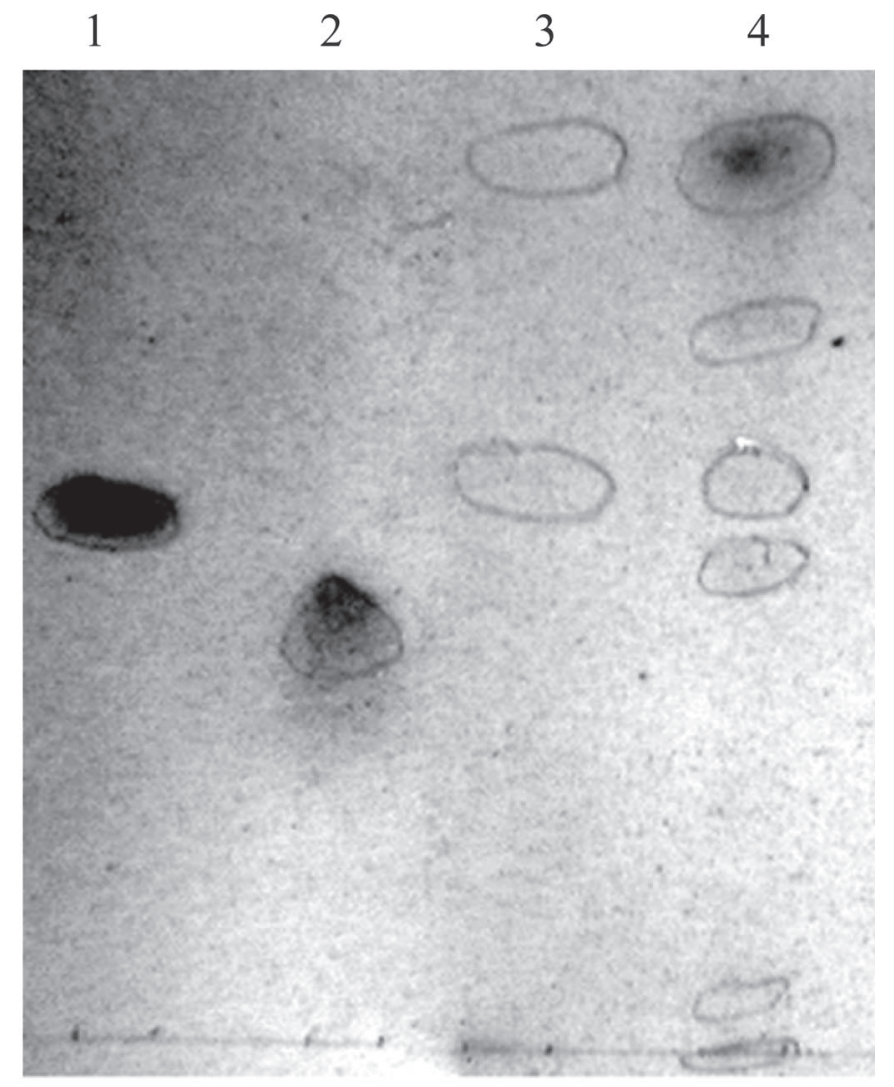

\begin{tabular}{cccc} 
Cholesterol & $\begin{array}{c}\text { Oleic } \\
\text { Acid }\end{array}$ & $\begin{array}{c}\text { Dipalmitoyl- } \\
\text { glycerol }\end{array}$ & $\begin{array}{c}\text { BM } \\
\text { MFGM }\end{array}$ \\
\cline { 1 - 2 } & &
\end{tabular}

Standards

Figure 4. Thin layer chromatographic (TLC) separation of fraction 1 from the iatrobead column chromatography of dual-phase extract of buttermilk milk fat globule membrane (BM MFGM). Fraction 4.5:1 (1) from the iatrobead column chromatography of the dual-phase extraction of BM MFGM (lane 3) was separated by silica gel TLC using chloroform:methanol (30:1) as the solvent. Lipids were fluorescently detected with primulin (circled bands) and carbohydrates were detected with orcinol in sulfuric acid. Cholesterol (lane 1) and oleic acid (lane 2) were run as standards. This image is representative of a single experiment.

ides, particularly those containing C10:0 and C12:0 fatty acids, protect against foodborne gastroenteritis (Sprong et al., 2001) and have direct antibacterial and antiviral activities (Hamosh, 1991; Isaacs and Thormar, 1991; Hamosh et al., 1999). In addition, our previous work showed a direct inhibitory effect of oleic acid isolated from bovine colostrum on the adhesion of Cryptosporidium parvum sporozoites to host cells (Schmidt and Kuhlenschmidt, 2008). Taken together, these data and the work presented here suggest that specific lipids derived from milk may serve as natural inhibitors of host cell-microbe interactions. Future studies are needed to determine the potential for MFGM lipids to inhibit RV
Table 5. Comparison of the anti-infective activity of fractions resulting from the iatrobead dual-phase organic extraction of milk fat globule membrane (MFGM) isolated from buttermilk (BM) against a neuraminidase-sensitive rotavirus strain $(\mathrm{OSU}-\mathrm{RV})^{1}$

\begin{tabular}{lc}
\hline Item & $\begin{array}{c}\% \text { of MEM } \\
\text { control }\end{array}$ \\
\hline MEM control & $100 \pm 10.4$ \\
BM organic extract ${ }^{2}$ & $8.5 \pm 1.5$ \\
Iatrobead fractions (chloroform:methanol) $^{\text {Nonpolar (4.5:1) }}$ & \\
1 & $6.0 \pm 1.0$ \\
2 & $56.5 \pm 3.5$ \\
3 & $51.0 \pm 0.0$ \\
4 & $48.5 \pm 5.5$ \\
5 & $67.7 \pm 3.0$ \\
Polar (1:1) & $63 \pm 0$ \\
2 & $53.8 \pm 16.6$ \\
\hline
\end{tabular}

${ }^{1}$ Percentage infectivity relative to that of minimal essential medium (MEM) control measured using focus-forming unit assay; means \pm SEM of duplicate wells per dose.

${ }^{2}$ Relative to the total weight lipids isolated from the MFGM powders.

infectivity in vivo. Isolated lipids could be fed directly to the animals or intact MFGM could be fed in an MFGMenriched diet and bioactive lipids (Hamosh, 1991; Isaacs and Thormar, 1991) could be released within the small intestine during the process of digestion.

\section{CONCLUSIONS}

Bovine milk appears to be a rich source of lipids with anti-infective properties. Lipid components associated with MFGM appear to contribute in large part to the anti-RV activity associated with the bovine MFGM, although further research is required to define the specific lipids responsible for this activity, as well as the mechanism of action. In addition, given the large quantities of whey generated from buttermilk and cheese production (Walstra et al., 1999; USDA-NASS, 2001), it is worth exploring value-added uses for MFGM isolated from these sources.

\section{ACKNOWLEDGMENTS}

This research was funded by US Department of Agriculture-Cooperative State Research, Education, and Extension Service ILLU Animal Health funds project \#ILLU888-930 at the University of Illinois (to M.S.K.), USDA NRI 2002-35204-12613 at the University of Illinois (to M.S.K.), and CSU Agricultural Research Initiative, California Dairy Research Foundation to California Polytechnic State University, San Luis Obispo (to R.J.F.). K.L.F. was the recipient of Abbott Veterinary Medical Scholars Fellowship from the College of Veterinary Medicine at the University of Illinois. The authors acknowledge William P. Hanafin (Department of Pathobiology, University of Illinois, 
Urbana) for his assistance with the FFU assays, Pierre Morin and Andrea Laubscher (Dairy Science Department, California Polytechnic State University, San Luis Obispo) for manufacture of MFGM extracts, and Marcia Monaco (Department of Food Science and Human Nutrition, University of Illinois. Urbana) for assistance with statistical analyses.

\section{REFERENCES}

Andres, A., S. M. Donovan, T. B. Kuhlenschmidt, and M. S. Kuhlenschmidt. 2007. Isoflavones at concentrations present in soy infant formula inhibit rotavirus infection in vitro. J. Nutr. 137:20682073.

Astaire, J. C., R. Ward, J. B. German, and R. Jiménez-Flores. 2003. Concentration of polar MFGM lipids from buttermilk by microfiltration and supercritical fluid extraction. J. Dairy Sci. 86:22972307.

Baumann, A., A. Underhaug Gjerde, M. Ying, C. Svanborg, H. Holmsen, W. R. Glomm, A. Martinez, and Ø. Halskau. 2012. HAMLET forms annular oligomers when deposited with phospholipid monolayers. J. Mol. Biol. 418:90-102.

Bojsen, A., J. Buesa, R. Montava, A. S. Kvistgaard, M. B. Kongsbak, T. E. Petersen, C. W. Heegaard, and J. T. Rasmussen. 2007. Inhibitory activities of bovine macromolecular whey proteins on rotavirus infections in vitro and in vivo. J. Dairy Sci. 90:66-74.

Cavaletto, M., M. G. Giuffrida, and A. Conti. 2004. The proteomic approach to analysis of human milk fat globule membrane. Clin. Chim. Acta 347:41-48.

Folch, C. J., M. Lees, and G. H. Sloane Stanley. 1957. A simple method for the isolation and purification of total lipids from animal tissues. J. Biol. Chem. 226:497-509.

Gallier, S., D. Gragson, C. Cabral, R. Jiménez-Flores, and D. W. Everett. 2010. Composition and fatty acid distribution of bovine phospholipids from processed milk products. J. Agric. Food Chem. 58:10503-10511.

Hamosh, M. 1991. Free fatty acids and monoglycerides: Anti-infective agents produced during the digestion of milk fat by the newborn. Adv. Exp. Med. Biol. 310:151-158.

Hamosh, M., J. A. Peterson, T. R. Henderson, C. D. Scallan, R. Kiwan, R. L. Ceriani, M. Armand, N. R. Mehta, and P. Hamosh. 1999. Protective functions of human milk: The milk fat globule. Semin. Perinatol. 23:242-249.

Hirmo, S., S. Kelm, and M. Iwersen. 1998. Inhibition of Helicobacter pylori sialic acid-specific haemagglutination by human gastrointestinal mucins and milk glycoproteins. FEMS Immunol. Med. Microbiol. 20:275-281.

House, J. A. 1978. Economic impact of rotavirus and other neonatal disease agents of animals. J. Am. Vet. Med. Assoc. 173:573-576.

Isaacs, C. E., and H. Thormar. 1991. The role of milk-derived antimicrobial lipids as antiviral and antibacterial agents. Adv. Exp. Med. Biol. 310:159-165.

Keenan, T. W., and S. Patton. 1995. The structure of milk: Implication for sampling and storage. The milk lipid globule membrane. Pages 5-62 in Handbook of Milk Composition. R. G. Jensen, ed. Academic Press, San Diego, CA.

Koopman, J. S., V. J. Turkisk, A. S. Monto, F. E. Thompson, and R. E. Isaacson. 1984. Milk fat and gastrointestinal illness. Am. J. Public Health 74:1371-1373.

Kuchta, A. M., P. M. Kelly, C. Stanton, and R. A. Devery. 2012. Milk fat globule membrane-A source of polar lipids for colon health? A review. Int. J. Dairy Technol. 65:315-333.

Kuhlenschmidt, T. B., W. P. Hanafin, H. B. Gelberg, and M. S. Kuhlenschmidt. 1999. Sialic acid dependence and independence of group A rotaviruses. Adv. Exp. Med. Biol. 473:309-317.

Kvistgaard, A. S., L. T. Pallesen, C. F. Arias, S. Lopez, T. E. Petersen, C. W. Heegaard, and J. T. Rasmussen. 2004. Inhibitory effects of human and bovine milk constituents on rotavirus infections. J. Dairy Sci. 87:4088-4096.
Le, T. T., T. Van de Wiele, T. N. H. Do, G. Debyser, K. Struijs, B. Devreese, K. Dewettinck, and J. Van Camp. 2012. Stability of milk fat globule membrane proteins toward human enzymatic gastrointestinal digestion. J. Dairy Sci. 95:2307-2318.

Mather, I. H. 2000. A review and proposed nomenclature for major proteins of the milk-fat globule membrane. J. Dairy Sci. 83:203247.

Newburg, D. S., J. A. Peterson, G. M. Ruiz-Palacios, D. O. Matson, A. L. Morrow, J. Shults, M. L. Guerrero, P. Chaturvedi, S. O. Newburg, C. D. Scallan, M. R. Taylor, R. L. Ceriani, and L. K. Pickering. 1998. Role of human-milk lactadherin in protection against symptomatic rotavirus infection. Lancet 351:1160-1164.

Parodi, P. W. 1999. Conjugated linoleic acid and other anticarcinogenic agents of bovine milk fat. J. Dairy Sci. 82:1339-1349.

Peterson, J. A., M. Hamosh, C. D. Scallan, R. L. Ceriani, T. R. Henderson, N. R. Mehta, M. Armand, and P. Hamosh. 1998. Milk fat globule glycoproteins in human milk and in gastric aspirates of mother's milk-fed preterm infants. Pediatr. Res. 44:499-506.

Ramig, R. F. 2004. Pathogenesis of intestinal and systemic rotavirus infection. J. Virol. 78:10213-10220.

Rolsma, M. D., H. B. Gelberg, and M. S. Kuhlenschmidt. 1994. Assay for evaluation of rotavirus-cell interactions: Identification of an enterocyte ganglioside fraction that mediates group A porcine rotavirus recognition. J. Virol. 68:258-268.

Rolsma, M. D., T. B. Kuhlenschmidt, H. B. Gelberg, and M. S. Kuhlenschmidt. 1998. Structure and function of a ganglioside receptor for porcine rotavirus. J. Virol. 72:9079-9091.

Schmidt, J., and M. S. Kuhlenschmidt. 2008. Microbial adhesion of Cryptosporidium parvum: Identification of a colostrum-derived inhibitory lipid. Mol. Biochem. Parasitol. 162:32-39.

Schroten, H., F. G. Hanisch, R. Plogmann, J. Hacker, G. Uhlernbruch, R. Nobis-Bosch, and V. Wahn. 1992. Inhibition of adhesion of Sfimbriated Escherichia coli to buccal epithelial cells by human milk fat globule membrane components: A novel aspect of the protective function of mucins in the nonimmunoglobulin fraction. Infect. Immun. 60:2893-2899.

Spitsberg, V. L. 2005. Bovine milk fat globule membrane as a potential nutraceutical. J. Dairy Sci. 88:2289-2294.

Sprong, R. C., M. F. Hulstein, and R. Van der Meer. 2001. Bactericidal activities of milk lipids. Antimicrob. Agents Chemother. 45:1298-1301.

Sprong, R. C., M. F. E. Hulstein, and R. Van der Meer. 2002. Bovine milk fat components inhibit food-borne pathogens. Int. Dairy J. 12:209-215.

Svennerholm, L., and P. Fredman. 1980. A procedure for the quantitative isolation of brain gangliosides. Biochim. Biophys. Acta 617:97-109.

USDA-NASS (Department of Agriculture-National Agricultural Statistics Service). 2001. Bulletin. USDA-NASS, Washington, DC. http://www.ers.usda.gov/data-products/food-availability(per-capita)-data-system.

Walstra, P., T. J. Geurts, A. Noomen, A. Jellema, and M. A. J. S. van Boekel. 1999. Butter. Pages 485-515 in Dairy Technology - Principles of Milk Properties and Processes. Marcel Dekker Inc., New York, NY.

Wang, X., S. Hirmo, R. Millen, and T. Wadstrom. 2001. Inhibition of Helicobacter pylori infection by bovine milk glycoconjugates in a BALB/cA mouse model. FEMS Immunol. Med. Microbiol. $20: 275-281$.

White, T., S. Bursten, D. Federighi, R. A. Lewis, and E. Nudelman. 1998. High-resolution separation and quantification of neutral lipid and phospholipid species in mammalian cells and sera by multi-one-dimensional thin-layer chromatography. Anal. Biochem. 258:109-117.

Widdowson, M.-A., J. S. Bresee, J. R. Gentsch, and R. I. Glass. 2005. Rotavirus disease and its prevention. Curr. Opin. Gastroenterol. $21: 26-31$.

Yolken, R. H., J. A. Peterson, S. L. Vonderfecht, E. T. Fouts, K. Midthun, and D. S. Newburg. 1992. Human milk mucin inhibits rotavirus replication and prevents experimental gastroenteritis. J. Clin. Invest. 90:1984-1991. 